\title{
Freud's dream analysis of "Tell Me Your Dreams" by Sydney Sheldon
}

\author{
Amrita Roy, \\ Postgraduate Student of English Literature with Communication Studies, \\ Christ (deemed to be) University, \\ Delhi
}

\begin{abstract}
As humans, our minds are divided into various different parts, and it is often our experiences that help shape the person we are. "Sigmund Freud viewed dreams as "the royal road" to the unconscious and developed dream analysis, or dream interpretation, as a way of tapping into this unconscious material." (Aurora, 389-410). This paper tries to analyze the different identities that reside within Ashley Patterson, the protagonist in "Tell Me Your Dreams," a masterpiece by none other than Sydney Sheldon, how Freud's dream analysis help us understand the chaotic state of Ashley's mind and bring us closer to the origin of her nightmares. This paper will closely review the novella by Sheldon. Keeping it as the primary source, the report will uncover the various conditions that can trigger the defense mechanism of our ego and create multiple personalities as a result. It is a descriptive paper as the writer obtains information from reviewing earlier works and the novel at large and draws a conclusion using it. The research technique used for the report is an extensive study of various library and scholarly articles on similar topics, information is gathered in the forms of books, articles, encyclopedias, or literary reviews that may have related to this study are collected and taken as the sources.
\end{abstract}

Keywords: Dissociation, Dream Analysis, Personalities, Trauma, Childhood.

\section{Introduction}

Literary works exist to give shape to society. These works are often a result of constant societal influence through various conditions such as political, religious, economic, and cultural. The novel is one form of literature (Ncc.edu Editor, 2014). Literature often tries to reflect on the good 
values and their counterparts that society creates. "In its zeal to correct things, literature reflects the tribulations of the community; its sole purpose is to make the organization realize its mistakes and make amends. It also tasks to showcase the virtues and the good values that are inherently present in society for people to emulate. Literature is considered to be an imitation of human action, and hence, it generally tries to portray the deepest and darkest thoughts of the human mind and what they say and do in society. In literature, we find narratives that are made to reflect on the happenings of human life and action through the characters who, by their words, action and reaction, convey particular messages for the purpose of education, information, and entertainment. It is impossible to seek out a piece of literature that excludes the attitudes, morale, and values of the society since no writer has been mentioned utterly unexposed to the world around him. (Duhan, 2015). It is often fictional, that is not based on actual events but something that birthed out of one's imagination, and often written in a narrative style. A set of circumstances is described so that they give the readers a false sense that it is actually happening or has already taken place. From this, we can draw a clear relation between literature and society. In The Republic, for instance, Plato presages both Mme. de Staël's treatise of 1800, which was the primary to debate cross-national differences in literature, and later notions of literary reflection together with his idea of imitation. What is new, however, is that the relative legitimacy of the study of literature within the discipline of sociology. Literature is an imitation of society is a well-known fact that has been widely accepted.

Tell Me Your Dreams" is one of the most famous novels by author Sydney Sheldon. Sheldon was born in Chicago. Illinois, in 1917, is one of the best-known writers of all time. He sold his first work at the age of 10, which was a poem written by him. At the start of 1937 , Sydney Sheldon gave a shot at writing scripts for Hollywood. He finally managed to sell one of his screenplays, 'South of Panama,' to a studio for 250 dollars in 1941. Sheldon was a famed writer and proudly served the army as an air force pilot during the 1st world war. Some of his most significant contributions are to MGM studios and paramount studios. Sydney's first novel was published in 1969, called "The Naked Face." Other famous works by him include "Master of The Game," "Bloodline," "Nothing Lasts Forever," "Are You Afraid of The Dark?" etc. Sheldon specializes in suspenseful thrillers that are sure to keep you at the edge of your seats.

At the very beginning itself, Sheldon establishes her three women protagonists, Ashley Patterson, Toni Prescott, and Alette Peters. Ashley is a shy and introverted girl, often described 
by those around her as a workaholic. The story picks up momentum when one of these three women comes home to "You Will Die" written on her mirror in bold red lipstick. All these three women aren't remotely similar to each other, with just one exception, they have all been subjected to hostility by their mothers. She was often being called good for nothing, which influences their present personalities greatly. As the plot moves ahead, we see Ashley worrying about someone following and stalking her. Then one day, when she comes home to a messed up house with all her belongings scattered on the floor and "You Will Die" written in bold red color on the mirror, all her worries are confirmed. She gets even more worried when a series of murders start taking place near her, although the cops confirm that it was a woman who was being suspected of committing those murders as both the victims were male and they were caught having sex just before they were killed and castrated. To give rest to Ashley's concerns, a cop is assigned to safeguard her and protect her at all times, but the very next day, even he is found dead. When the cops begin to investigate the murder that took place in Ashley's apartment, they come across a crucial clue, a piece of evidence that will change the face of the entire investigation. Near the body lies a gift box sent by Toni Prescott, soon Toni, Ashley, and Alette. All three women get arrested for the same crime. It is revealed here that they were but one woman, Ashley Patterson. Ashley suffered from a unique disorder called Dissociative Identity Disorder (DID), also knows as multiple personality disorder in layman's language. This disorder often results in one person having various personalities residing within them.

After going on trial for murder, Ashley is eventually acquitted because of insanity when a defense attorney draws out the violent Toni and juxtaposes her with the much calmer Ashley and Alette. As a result of the verdict, Ashley is sent to a mental asylum, where she is treated by Dr. Gilbert. Through his treatment, it is learned that Ashley was often sexually abused by her own father. When Ashley was abused by her father for the very first time, her ego as a defense mechanism created Toni as a receptacle for all of Ashley's burgeoning hatred toward her father and men in general. However, when Ashley was abused again in her teens, the personality of Alette was created to deal with the shame. Just when he thought that he had gotten through to her and she was finally healed and clear to leave, it was later realized as a scheme planned by Toni to escape the asylum. Ashley had decided to live her life with both Toni and Alette residing within her. Later on, when she got to know that her father was remarrying a woman with a three-yearold daughter that she decided to put an end to his dad's dirty deeds once and for all. They find out 
that he is staying in the Hamptons, and the book ends with Toni on her way to his location, singing in a carefree manner because she is about to kill her father, finally, which in many ways is what her whole personality was created to do.

\section{What is multiple personality disorder?}

Dissociative identity disorder (DID), in a layman's term, refers to the presence of two or more personalities present in the same person as a result of a defense mechanism that may have gotten triggered due to trauma. In this case, Toni and Alette were two personalities created by Ashley's unconscious mind in order to protect them from further harm. Thus, it is also known as split or multiple personality disorder. There are several conditions found to be associated with this disorder, including depression, self-harm, post-traumatic stress disorder (PTSD), trauma is seen as one of the biggest reasons for triggering DID, substance use disorder, borderline personality disorder or anxiety, and conversion or somatoform disorder are other issues that can trigger DID. It also includes the unexplained loss of personal information from one's memory. (Cureus, 2018). Dissociative states usually emerge as a disconnection and switch between different mental conditions due to a disconnection between memories related to traumatic or stressful experiences that disturb conscious awareness and understanding of the self (Li and Spiegel, 1992; Putnam, 1997; Bob, 2003; Spiegel, 2012). Dissociation can also be considered as a partial or total disconnection or breakage of a link between memories from the past, awareness of identity and immediate sensations, and control of bodily movements often resulting from traumatic experiences, intolerable problems, or disturbed relationships (Li and Spiegel, 1992; Bob, 2003; Colman, 2003).

As we have already learned, DID is majorly caused by the traumatic experiences trapped in our unconscious. As a result, the unconscious creates different personalities pole apart from its own as a defense mechanism to protect itself from the nightmarish memories of the trauma. Dream analysis can be seen as a therapeutic treatment for psychoanalysis. Freud has time and again emphasized dream analysis being the royal road to our unconscious, and in order to study the mysteries of the unconscious mind, he developed dream analysis or dream interpretation. It was seen as a way of tapping into this unconscious mind and was often used to treat many disorders, including DID. (Freud). According to Freud, dissociative disorders were classified as hysteria, more prevalent in women than men. Sigmund Freud regarded dissociation to be a standard means through which the ego defended itself against unacceptable unconscious 
thoughts - and expression of unconscious conflict. Historically, dissociative disorders were classified as forms of hysteria, more prevalent in women than men. Sigmund Freud regarded dissociation to be a standard means through which the ego defended itself against unacceptable unconscious thoughts - and expression of unconscious conflict. Pierre Janet, one of Freud's contemporaries, had differing opinions and considered dissociation as abnormal - detachment from conscious awareness occurred only as a part of psychopathology (Otmans \& Emery, 2010). Freud's views on dissociative tendencies remained quite prevalent and were followed by almost everyone. Some critics of his complained about his theory being overly focused on the unconscious and the memories stored within the unconscious realm. They found it absurd and lacking logic. Despite criticisms, his approach was believed to the masses and was used by various researchers to expand the scope of the study of dissociative personality disorder.

\section{Conclusion}

Ashley Patterson from "Tell Me Your Dreams" has multiple personality disorders, which, as described by Freud, is a defense mechanism of our ego that gets triggered due to traumatic childhood experiences. Dissociation is still considered rare, although many individuals will often go undiagnosed or misdiagnosed for many years, thus delaying effective treatment. It is vital as practitioners that acknowledgment is given to the existence of dissociation while remaining vigilant to the impact diagnosis can have on a client's experience. Ashley Patterson, due to her childhood trauma inflicted upon her by her father, who sexually abused her multiple times throughout her growing phase, Ashley developed various personalities to safeguard herself from her childhood memories. It is seen and understood that one of her personalities was created entirely to kill her father. Freud has time and again established that dissociative personalities result from a defense mechanism created by our ego as a safeguard to protect us from traumatic memories. The memories trigger often get pushed to the unconscious mind and are forgotten.

Freud's dream analysis can be used to uncover these memories and understand the various different personalities created within a person.

\section{References}

Aurora, R. N., Zak, R. S., Auerbach, S. H., Casey, K. R., Chowdhuri, S., Karippot, A., \& Maganti, R. K. (2010). “Best Practice Guide for The Treatment of Nightmare Disorder in Adults". Journal of Clinical Sleep Medicine, 6(4), 389-401. Retrieved from American Academy of Sleep Medicine. 
Calhoun, Craig 1989 "Social Issues in the Study of Culture." Comparative Social Research 11:1-29.

NCC. Edy Editor 2014. Definition of Novel. http://www.nvcc.edu/home/ataormina/novels/history/define.html. October 2014

Li D., Spiegel D. (1992). A neural network model of dissociative disorders. Psychiatr. Ann. 22 144-147. 10.3928/0048-5713-19920301-11

Oltmanns, T., and Emery, R., E. (2010). Abnormal psychology. (6th ed.). Upper Saddle River, New Jersey: Prentice-Hall.

American Psychiatric Association. (2000). Diagnostic and statistical manual of mental disorders. (4th ed.). Washington, USA: American Psychiatric Association.

Van Heugten-van der Kloet D and Lynn SJ (2020) Dreams and Dissociation-Commonalities as a Basis for Future Research and Clinical Innovations. Front.

Petr Bob and Olga Louchakova. Dissociative states in dreams and brain chaos: implications for creating awareness. Front Psychol. 2015 Sep 7. doi: 10.3389/fpsyg.2015.01353

Coon, D. (2005). Psychology A Journey (2nd ed.). Belmont, CA: Thomson Wadsworth.

Davies Anda, A brief Introduction to Dissociation, AIPC Article Library. May 2010. 